\title{
Fibrous Polymeric Buccal Film Formulation, Engineering and Bio-Interface Assessment
}

Kazem Nazari ${ }^{1}$, Eleni Kontogiannidou ${ }^{2}$, Rita Haj Ahmad ${ }^{1}$, Dimitrios Andreadis ${ }^{2}$, Manoochehr Rasekh ${ }^{1}$, Nikolaos Bouropoulos ${ }^{3,4}$, Sussana van Der Merwe ${ }^{5}$, Ming-Wei Chang $^{6,7}$, Dimitrios G Fatouros ${ }^{* 2}$, Zeeshan Ahmad ${ }^{* 1}$

${ }^{1}$ Leicester School of Pharmacy, De Montfort University, Leicester, LE1 9BH, UK

${ }^{2}$ Aristotle University of Thessaloniki, Department of Pharmacy, Thessaloniki, Greece

${ }^{3}$ Department of Materials Science, University of Patras, 26504 Rio, Patras, Greece

${ }^{4}$ Foundation for Research and Technology, Hellas-Institute of Chemical Engineering and High Temperature Chemical Processes (FORTH/ICE-HT), P.O. Box 1414, GR-26504 Patras, Greece

${ }^{5}$ School of Pharmacy and Biomedical Sciences, St. Michael's Building, White Swan Road, Portsmouth, PO1 2DT

${ }^{6}$ College of Biomedical Engineering and Instrument Science, Zhejiang University, Hangzhou 310027, China

${ }^{7}$ Zhejiang Provincial Key Laboratory of Cardio-Cerebral Vascular Detection Technology and Medicinal Effectiveness Appraisal, Zhejiang University, Hangzhou 310027, China

Co-corresponding authors:

Zeeshan Ahmad, zahmad@dmu.ac.uk

Dimitrios G Fatouros, dfatouro@pharm.auth.gr, 


\begin{abstract}
Polymer based dosages form the mainstay of drug delivery systems either as simple matrix carrier materials or active release behaviour modulating agents. In addition, several techniques have been developed further to deliver novel polymeric structures. One such method is electrospinning (ES); a maturing process which is operational at the ambient environment and enables drug loading (in molecularly dispersed form) directly into a fibrous polymer matrix system. Since there is an impending need to address healthcare challenges arising from an increase in the aging population (requiring enhanced treatments), the ES method was used to develop fibrous polymer composite-indomethacin (INDO) films for potential use in the buccal region. Films were assessed for their inter-facial behaviour at biointerfaces (in-vitro and ex-vivo). Polymeric excipients possessing an established profile for commercial dosage form development were selected. Fibrous films (all fibre components $<400 \mathrm{~nm}$ ) were characterised using DSC, TGA, FTIR, Raman and XRD. DSC and XRD demonstrated INDO change from crystalline to amorphous state. FTIR and Raman data suggest INDO, PVP and co-polymers (Methocel TM E5, Methocel TM E15 and Tween ${ }^{\circledR} 80$ ) were integrated in stable fashion into filamentous structures via ES.Variable INDO release behaviour from several matrices was observed suggesting a potential route to tailor drug release based on polymeric excipient use and ratio. Furthermore, permeation studies using a porcine buccal model demonstrated sustained permeation once dosages are attached to the buccal mucosa. The insoluble nature of cellulose excipients were used to promote sustained release while the use of Tween ${ }^{\circledR} 80$ surfactant was used to enhance permeation of INDO through polymer interaction with excised tissue. Finally, histology studies indicate polymer excipient selection impacts the bio-interface. In summary, a facile approach to formulate, encapsulate and engineer fibrous polymeric buccal films (on demand) is shown. The method enables drug dispersion directly within the composite polymeric system, which has a clear impact on drug release, in-vitro and ex-vivo bio-interaction.
\end{abstract}

Keywords: electrospinning, buccal delivery, in vitro, ex-vivo, indomethacin, bio-interface 


\section{Introduction}

Polymer selection for the design and development of drug dosage forms is as important as the nominated active pharmaceutical ingredient (API) [1]. Formulation and selective use of excipients enable specific chemical and physical properties including manufacturing method, dosage stability, packaging, handling and bio-interface interactions. A vast variety of polymers, from both synthetic and naturally occurring classes, are used for commercial drug dosage manufacturing and optimisation. Selection is often derived on the basis of material suitability when considering engineering steps during product development (e.g. including particle or fibre engineering [2,3]).

The buccal route for API administration has gained popularity over the last decade due to advances in drug discovery (coupled with potential opportunistic therapies) [4,5], on-demand dosage form development [6] and also to overcome disadvantages associated with conventional oral dosage forms (e.g. difficulty swallowing or tolerating the enteric route) $[7,8]$. Several methods to develop or formulate buccal drug delivery systems have been explored through innovative developments in films, patches, tablets and even capsules [9]. Rapid drug absorption (from various dosage form types e.g. pill or film) has been shown in the buccal cavity, in addition to greater patient compliance compared with other oral transmucosal administration routes [10]. Furthermore, greater volume of vascularised tissue and blood vessels at this location indicate potential entry into systematic circulation [11], possibly through the jugular vein $[7,10,12]$. Avoiding drug hydrolysis (often encountered in the gastrointestinal tract), enzymatic and acidic action, as well as bypassing first-pass metabolism are all drivers for the development of buccal drug delivery systems [10]. In terms of interactions, a characterise feature of the buccal mucosa is fast cellular recovery suggesting minimal damage to the administration site upon application [10,13-15]. The anatomical and physiological property of the buccal region leads to high drug bioavailability and fast onset of action. One such active which has been explored for buccal delivery is nitroglycerin. The API has been developed into various sublingual dosage forms with notable advances in ointments, gels, film patches and tablets (e.g. low molecular weight heparins) [16].

Several engineering methods have been developed to prepare buccal dosage forms which include solvent casting [17] and hot melt extrusion [6]. Both methods exhibit advantages and limitations during formulation preparation. Electrospinning (ES) is an evolving and maturing 
engineering method with extensive recent interest in the pharmaceutical arena $[8,18,19]$. This one-step technique has been developed to fabricate fibrous films loaded or co-loaded with API (at required quantities in-situ) at the ambient environment [20]. Process aspects (applied voltage, flow rate and the distance between tip of processing nozzle to collecting platform) and pre-formulated material properties (e.g. viscosity, density, electric conductivity and surface tension) are often explored and correlated with processing viability [21-23]. ES has numerous sister processes namely, electrospraying [24], EHD printing [25], microbubbling [26] and these can be complexed further through the use of two or more processing needles $[27,28]$.

Indomethacin (INDO) is a non-steroidal anti-inflammatory drug (hydrophobic) available in crystalline form; which is used for the treatment of common illness such as fever, mild to moderate pain, swelling and to relieve symptoms of arthritis. INDO inhibits the production of prostaglandins which are responsible for inflammation and pain [29,30]. As a model drug, enhancement of INDO solubility and dissolution at the buccal site requires amorphisation. This is crucial and enhances drug bioavailability as its increases molecular mobility when compared with the crystalline form [31]. Numerous studies have focused on the development of thin film platforms and the vast majority of these have utilised in-vitro or ex-vivo studies for evaluation, although greater bio-interface evaluation is needed. Furthermore, assessment using various models (ex-vivo and in-vitro) and how they correlate is valuable.

In the present work, amorphous fibrous INDO films were prepared using Polyvinylpyrolidone (PVP), Methocel TM (E5) premium, Methocel TM (E15) and Tween ${ }^{\circledR} 80$ via single step ES. Films were characterised for their size and their components (presence and stability) using spectral techniques. Drug loading and encapsulation efficiency of the process was determined. INDO state was also assessed using XRD analysis and the release behaviour of the active was explored in vitro (PBS), while permeation was evaluated using an ex-vivo (porcine) model. PBS spreading behaviour on engineered polymer films was evaluated using surface contact angle measurements. Finally, buccal mucosa histology (porcine) was performed to assess film bio-interface tolerance. 


\section{Materials and Methods}

\section{Materials}

Indomethacin (INDO), polyvinylpyrrolidone, PVP, (high molecular weight $1.3 \times 10^{6} \mathrm{~g} / \mathrm{mol}$ ) and phosphate buffer saline were purchased from Sigma-Aldrich (Gillingham, UK). Ethanol (HPLC grade) was obtained from Fisher Scientific (Loughborough, UK).Methocel TM (E5) premium, Methocel ${ }^{\mathrm{TM}}$ (E15) and Tween $^{\circledR} 80$ were purchased from DOW Chemical Company-UK.

\section{Solution preparation}

The compositions of all formulations used in this study are listed in Table 1. $75 \mathrm{~mL}$ of individual polymeric solutions (sufficient for preliminary rheological assessment and film preparation) were prepared using ethanol and distilled water (80:20 ratio, respectively) as the vehicle. PVP (5\% w/w) was dissolved in the vehicle using mechanical stirring (Jenway, Staffordshire, UK) for 30 minutes at ambient conditions $\left(24{ }^{\circ} \mathrm{C}\right)$. A known quantity of selected co-polymer and INDO (5\% w/w of PVP) were added to each formulation under mechanical stirring until complete dissolution. Several studies have used similar drug loading concentrations for fibrous or electrospun materials [32,33]. Paraffin film was used to seal the solutions to prevent solvent evaporation. Finally, two additional solutions were prepared by adding Tween ${ }^{\circledR} 80$ to $(5 \%$ w/w of PVP) existing formulations.

\section{Preparation of electrospun fibres and films}

Polymeric solution formulations were infused into an electrically conducting capillary needle (possessing inner and outlet diameters of 0.3 and $0.5 \mathrm{~cm}$, respectively) at a rate of $20 \mu \mathrm{L} / \mathrm{min}$. Infusion was controlled using a Harvard Apparatus 11-Elite syringe pump (Harvard Apparatus, Edenbridge, UK). An electric field $(15 \pm 2 \mathrm{kV})$ was supplied via a high voltage power supply (Glassman High Voltage, Inc., High Bridge, New Jersey). Glass slides (Microscope Slide, WWR, Leicester, UK) were neatly layered with silicon coated paper (to ease film removal) and placed $15 \mathrm{~cm}$ beneath the needle outlet. Once collected, films were then stored in a petri dish. The ES set-up is shown in Figure 1a with the ES needle head shown in Figure 1b. During most electrohydrodynamic (EHDA) experimentations various liquid atomization modes are observed from dripping (Figure 1c), stable (Figure 1d) to multi-jet (Figure 1e) [34,35,36]. The stable jetting mode was determined for each formulation and was used to fabricate fibrous films, which were subsequently cut down to a suitable size (Figure 1f). 


\section{Microscopic imaging and size distribution}

Scanning electron microscopy (SEM) was performed using a SEM Carl Zeiss EVO ${ }^{\circledR}$ HD15 (Carl, Zeiss, Oberkochen, Germany). Fibres were mounted onto the sample holder (aluminium stub) using double sided tape. To prevent any overcharging, samples were covered with a thin film of gold by sputter coating (S150B, Edwards, Crawley, West Sussex, UK). Micrographs were examined and fibre diameters were analysed via SEM program Image Tool. The mean fibre diameter distribution and range was determined using 150 random measurements from each sample (assumed to be representative fibre morphology).

\section{X-ray diffraction studies (XRD)}

Sample crystallinity was evaluated with XRD analysis performed on a BrukerD8-Advance diffractometer, operating at $40 \mathrm{kV}$ and $40 \mathrm{~mA}$, using $\mathrm{Cu} \mathrm{Ka}$, at a scanning rate of 0.35 sec/step. Spectra were collected in the 20 angle from $10-50^{\circ}$.

\section{Differential scanning calorimetry (DSC)}

DSC analysis was performed using a PerkinElmer Jade DSC differential scanning calorimeter (PerkinElmer Ltd., Shelton, CT, USA). Samples (3.5 - $4.2 \mathrm{mg})$ were placed into an aluminium pan (Perkin Elmer) and sealed. Samples were heated from 20 to $200{ }^{\circ} \mathrm{C}$ at a heating rate of $10^{\circ} \mathrm{C} / \mathrm{min}$ under a nitrogen purge of $70 \mathrm{~mL} / \mathrm{min}$.

\section{Thermogravimetric analysis (TGA)}

Thermal behaviour of prepared fibres was analysed using a thermal gravimetric analyser TGA (Perkin Elmer Pyris 1 TGA). Each sample was placed in an aluminium pan (TGA, Perkin Elmer), weighted (7-10 mg) and heated at a temperature range of 20 to $800^{\circ} \mathrm{C}$ in a nitrogen atmosphere, using heating rate of $10^{\circ} \mathrm{C} / \mathrm{min}$.

\section{Fourier Transform infra-red spectroscopy (FTIR)}

The chemical structure of raw materials and prepared fibres was analysed using a Fourier Transform Infrared spectrophotometer (FTIR Platinum-ATR fitted with Bruker Alpha Opus 27 FT-IR). Infrared spectra were recorded in the range $4000-400 \mathrm{~cm}^{-1}$, obtained using an average 30 scans at a resolution of $4 \mathrm{~cm}^{-1}$ for each sample. 


\section{Raman spectroscopy}

Raman spectra were obtained using a FORAM ${ }^{\circledR}$ Raman spectrometer (Foster \& Freeman Ltd) equipped with a $785 \mathrm{~nm}$ laser; accumulating 30 scans at $4 \mathrm{~cm}^{-1}$ resolution. Raman spectra were collected between 3300 and $100 \mathrm{~cm}^{-1}$.

\section{Contact angle measurements}

Phosphate buffer (PBS, pH 6.8) contact angles on fibrous films were measured using "Theta light" (Biolin Scientific Attension, Stockholm, Sweden) contact angle measuring equipment. Formulations were electrospun onto glass slides for $\sim 30$ mins and then placed on the testing plate. Thereafter, PBS was micro-pipetted onto the films surface. Dynamic contact angles were assessed using a video monitor. Each sample was measured three times.

\section{PBS-Film contact time behavior}

Selected film formulations were electropsun directly onto glass slides using parameters determined during engineering. Glass coated slides were then immersed into PBS solution for known time intervals and removed. Subsequently, all residual PBS was rapidly dripped off from the substrate (through tilting mechanism) and films were allowed to dry for $48 \mathrm{~h}$. Samples were then analyzed using SEM for changes to fibre structure, integrity and potential precipitation effects.

\section{Drug loading capacity}

Precisely weighted amount $(1 \mathrm{mg})$ of all samples was dissolved in $3 \mathrm{~mL}$ of ethanol in capped glass vials under magnetic stirring for $15 \mathrm{~min}$ to ensure complete dissolution. The resulting solutions were centrifuged at 4,500 rpm for $15 \mathrm{~min}$, and quantification of INDO was performed on the resulting supernatants using UV-Vis analysis at 320nm (UV-Vis spectrophotometer, Shimadzu, UVmini-1240). Experiments were run in triplicate. Drug content was calculated according to the following equation [37].

$$
\text { Drug content }\left(\% \frac{\mathrm{w}}{\mathrm{W}}\right)=100 \times \frac{\mathrm{w}_{\mathrm{drug}}}{\mathrm{w}_{\text {drug loaded fibre }}} \text { Equation } 1
$$

\section{In vitro release studies}

Release studies were conducted in capped glass vials in an agitating water bath at $37{ }^{\circ} \mathrm{C} .5$ $\mathrm{mg}$ of each sample was sunk to the bottom of individual vials filled with $20 \mathrm{~mL}$ of PBS buffer solution $\mathrm{pH}$ 6.8. At predetermined time intervals, a $1 \mathrm{~mL}$ sample was withdrawn and 
replaced with an equal volume of fresh and preheated test medium $\left(37{ }^{\circ} \mathrm{C}\right)$ buffer solution. Samples were centrifuged at $2.500 \mathrm{rpm}$ for $15 \mathrm{~min}$, and the supernatants were analyzed with UV-Vis at $320 \mathrm{~nm}$. All experiments were repeated four times. The calibration curve of INDO in PBS pH 6.8 showed good linearity $\left(\mathrm{r}^{2}=0.999\right)$. INDO release kinetics was examined using the Higuchi model (this model was chosen as related studies indicate diffusive mechanisms for drug encapsulated within filamentous matrices [38, 39]) via Equation 2:

$$
\mathrm{Q}=\mathrm{K}_{\mathrm{H}} \mathrm{t}^{1 / 2} \quad \text { Equation } 2
$$

where $\mathrm{Q}$ is the amount of drug released in time $\mathrm{t}$ and $\mathrm{K}_{\mathrm{H}}$ is the Higuchi dissolution constant.

\section{Ex-vivo buccal permeation}

Porcine mucosal specimens (from a local slaughterhouse in Thessaloniki) were obtained from tissue removed from the inner cheek (buccal area) of freshly slaughtered pigs. After sampling, all specimens transferred to laboratory in ice-cold buffer (PBS) within $1 \mathrm{~h}$. Specimens were surgically treated to remove excesses of connective and adipose tissue until slides $700 \pm 100 \mu \mathrm{m}$.

Appropriate sections of mucosa were mounted in vertical Franz type diffusion cells with a diffusion area of $4.9 \mathrm{~cm}^{2}$ and a compartment volume of $15 \mathrm{~mL}$. Tissue disks were equilibrated for 10 min at $37{ }^{\circ} \mathrm{C}$ adding simulated plasma ( $\mathrm{pH}$ 7.4) in the acceptor compartment. In the donor compartment was then placed $20 \mathrm{mg}$ of each film in $1 \mathrm{~mL}$ of buffer solution simulating saliva ( $\mathrm{pH}$ 6.8). The diffusion studies were carried out at $37^{\circ} \mathrm{C}$, under stirring. At regular time intervals, samples $(1 \mathrm{~mL})$ were withdrawn from the acceptor compartment and the sample volume taken out was replaced by fresh fluid. Each experiment was carried out for 6 hours and results are reported as means \pm SD of three different experiments. Selected sample preparation stages are shown in Figures $\mathbf{2 a}$ (tissue) and $\mathbf{b}$ (permeation).

In all experiments, the drug transferred from the donor to the acceptor compartment was quantified using an HPLC system consisting of a LC-10 AD VP pump, an auto sampler model SIL-20A HT equipped with a $100 \mu \mathrm{L}$ loop and a UV-Vis detector model SPD-10A VP (SHIMADZU) using a RP-Amide C16, $15 \mathrm{~cm} \times 4.6 \mathrm{~mm}$ I.D., $5 \mu \mathrm{m}$ particles as column. UV detector was set at $264 \mathrm{~nm}$ for the detection of indomethacin. The mobile phase consisted of acetonitrile: $\mathrm{H}_{2} \mathrm{O} 50: 50(\mathrm{v} / \mathrm{v})$ with the addition of $100 \mu \mathrm{L}$ of $\mathrm{CH}_{3} \mathrm{COOH}$ per $100 \mathrm{~mL}$ of mobile phase. Flow rate was set at $1 \mathrm{~mL} / \mathrm{min}$ and the injection volume at $50 \mu \mathrm{L}$. The HPLC assay was 
performed at ambient temperature. All solvents were filtered through a $0.45 \mu \mathrm{m}$ nylon membrane and degassed prior to use. The retention time of the column was 9 minutes. The calibration curve of the drug showed good linearity $\left(\mathrm{r}^{2}=0.999\right)$ in the range of $0.5-10 \mathrm{ppm}$.

\section{Analysis of permeation data}

The steady state flux $\left(\mathrm{J}_{\mathrm{ss}}\right)$ across the epithelium were calculated using the following equation [40]

$$
\mathrm{J}_{\mathrm{ss}}=\mathrm{Q} / \mathrm{At}\left(\mu \mathrm{g} / \mathrm{cm}^{2} \mathrm{~h}^{-1}\right) \quad \text { Equation } 3
$$

where $\mathrm{Q}$ is the cumulative amount of drug penetrating the mucosa $(\mu \mathrm{g}), \mathrm{A}$ is the diffusional area $\left(\mathrm{cm}^{2}\right)$ and $\mathrm{t}$ is the total time of the experiment $(\mathrm{h})$.

The permeability coefficient (P) was then calculated by the relationship [41]

$$
\mathrm{P}=\mathrm{J}_{\mathrm{ss}} / \mathrm{Cd}(\mathrm{cm} / \mathrm{h}) \quad \text { Equation } 4
$$

where $\mathrm{Cd}$ is the drug concentration in the donor compartment $\left(\mu \mathrm{g} / \mathrm{cm}^{3}\right)$.

\section{Histological evaluation}

Abnormalities of the mucosal architecture after transport studies were evaluated using $4 \mu \mathrm{m}$ thick sections of each of the formalin-fixed and paraffin-embedded samples stained by conventional hematoxylin-eosin. Specimens were analyzed in an Olympus CX31 optical microscope and microphotographs were taken via the OLYMPUS analysis getIT software.

\section{Statistical analysis}

Differences in transport studies were evaluated by unpaired $t$-test. A one-way analysis of variance with Dunnett's multiple comparison test was performed by comparing formulations against formulation F1. The data were considered significantly different when the $p$-value was less than 0.05 .

\section{Results and Discussion}

\section{Fibre morphology and size distribution}

Fibrous membranes were engineered using all INDO (solution) formulations. Stable jetting was determined using a preliminary applied voltage $v s$. infusion rate experimental matrix to ensure near uniform fibre engineering. To achieve this stable jetting, several modes are encountered which become apparent for various types of media $[42,43]$ at the nozzle exit. In 
addition, various jetting modes have been developed based on material properties and needle alignment and these have an impact on the end structure [44, 45]. However, stable jetting windows were determined for INDO-PVP based formulations and were subsequently used to engineer fibrous films.

Figures 3a-e show surface morphology of various electrospun fibrous membranes with inset images displaying membrane width (thickness), obtained using horizontal and plan view microscopic analysis. All formulated fibres exhibit a smooth surface; albeit with variable diameter distributions. The difference is attributed to the inclusion of additional excipients and co-polymer ratios [8]. Figures $\mathbf{3 f - g}$ show diameter distributions of 150 randomly selected fibres from each electrospun membrane sample. The fibre diameter was noted to increase upon the inclusion of co-polymer (compared to PVP-INDO alone, F1). Samples F2 and F3 display mean fibre diameters of $810 \pm 300$ and $510 \pm 400 \mathrm{~nm}$, respectively. Differences to mean fibre diameter, however, were also impacted by type of co-polymer selected. For example, membranes prepared using Methocel $^{\mathrm{TM}}$ E15, possessed fibres with coarser diameters when compared to Methocel ${ }^{\mathrm{TM}}$ E5. Membranes comprising ES formulations F2 and F5 exhibit bell-shape fibre diameter distribution pattern, which is associated with enhanced drug (INDO) encapsulation resulting in coarser structures $[8,46]$.

\section{X-ray diffraction studies}

XRD patterns of electrospun fibrous films and neat INDO are shown in Figure 4. The X-ray diffraction pattern of pristine INDO indicates the active to possess a highly crystalline structure as multiple sharp diffraction peaks at $\left(\sim 2\right.$ theta $\left.=10-38^{\circ}\right)$ and principle peaks at 11.7, 16.7, 19.5, 21.6 and 21.6 observed [8]. The diffraction spectrum of all electrospun fibrous films (F1-F5) show a diffused background pattern with complete disappearance of all principle INDO peaks. This suggests INDO is well dispersed in fibrous matrices, yielding an amorphous state. The amorphous state provides several benefits, including accelerated drug release and enhanced drug solubility, which are valuable for bioavailability. However, this must be correlated with permeation behavior to gauge real benefit.

\section{Differential scanning calorimetry (DSC) and thermogravimetric analysis (TGA)}

Figure 5 shows DSC and TGA thermograms of electrospun INDO formulations. In its obtained form, INDO is crystalline and possesses a melting temperature $\left(T_{m}\right)$ of $\sim 164{ }^{\circ} \mathrm{C}$ (as shown in Figure 5a). This melting peak is no longer observed for electrospun samples, 
indicating the drug is dispersed throughout the polymer matrix post ES. Numerous studies have made use of the ES technique to engineer PVP fibres from the raw polymer [47, 48, 49]. In these, a broad endotherm arising at $\sim 90 \mathrm{C}$ has been reported which is also the case in this study for all samples prepared using INDO and PVP. The broad endotherm at this value is attributed to dehydration which is most likely due to loss of moisture often adsorbed by hygroscopic PVP polymer, the rate of which may be enhanced due to the increased surface area of fibrous structures. Furthermore, increasing the ES co-polymer formulation content provides greater polymeric matrix volume for active spacing and dispersion.

TGA was utilized to study thermal degradation behavior of fibrous INDO-polymer composite films. Figures 5c and $\mathbf{d}$ show TGA thermograms of electrospun formulations. In the current study, all fibrous films show two degradation steps; the first relates to weight loss in film formulation below $100{ }^{\circ} \mathrm{C}$, which is ascribed to evaporation of residual solvent or surface adsorbed moisture on fibrous (and porous) samples. The second weight loss step occurs in the range $350-500{ }^{\circ} \mathrm{C}$; and is attributed to degradation and decomposition of components comprising fibrous formulations such as PVP and other co-polymer excipients. All C-H, C-N, $\mathrm{C}=\mathrm{O}$ and $\mathrm{C}-\mathrm{C}$ bonds are compromised with temperatures exceeding $300{ }^{\circ} \mathrm{C}$; after which complete decomposition of PVP into nitrogen and carbon oxide powders is observed [50]. Previous studies indicate similar degradation steps [51].

TGA thermogram of PVP-INDO formulation (F1) shows the highest temperature associated with the second weight-loss step when compared with all other fibrous formulations, which incorporates a co-polymer excipient into the fibrous drug loaded film. INDO is loaded directly into filamentous matrices [8] and previous studies report that a shift in the maximum temperature (associated weight-loss step) can be used to validate drug entrapment within films [51]. The thermal degradation of a composite formulation is also driven by the active ingredient (drug) used; as both increase and decrease in the maximum temperature associated weight loss have been shown [51].

\section{Fourier Transform Infrared (FTIR) and Raman spectroscopic analysis}

Raman and FTIR spectroscopy were used to study structure and molecular conformation of fibrous films by probing band vibrations [52].

Figure 6 displays Raman and FTIR spectra for electrospun films. Figures $\mathbf{6 a}$ and $\mathbf{b}$ show Raman spectra obtained at $3300-300 \mathrm{~cm}^{-1}$ range. Several peaks were observed at $2884 \mathrm{~cm}^{-1}$ 
$(v(\mathrm{C}-\mathrm{H}))$ and $2220 \mathrm{~cm}^{-1}(v(\mathrm{C} \cong \mathrm{N}))$ in addition to a sharp peak at $3080 \mathrm{~cm}^{-1}$ which is ascribed to $\mathrm{O}-\mathrm{H}$ vibrational stretching of the carboxylic acid group in INDO. All formulations (F2-F5) show a new band at $2760-2770 \mathrm{~cm}^{-1}$ (corresponding to specific co-polymer deployed) along with a significant increase in peak intensity at $3072 \mathrm{~cm}^{-1}$ as compared with Raman spectra for F1 (PVP-INDO) which could be attributed to increased amorphous INDO content. The data suggests active (INDO), base polymer (PVP), co-polymers (Methocel TM E5, Methocel TM E15) and Tween ${ }^{\circledR} 80$ (where integrated) incorporate completely into filamentous structure by ES.

Figures $6 c$ and $\mathbf{d}$ show FTIR spectra at the wavelength range $4000-400 \mathrm{~cm}^{-1}$. PVP background is observed in all samples and various characteristic peaks for other excipients and the active are detected. Observed peaks were amide $\nu \mathrm{C}=\mathrm{O}$ at $1600 \mathrm{~cm}^{-1}$ which is due to vibrations arising from INDO's aromatic ring. In addition, absorption peaks are observed at 2980 and $1423 \mathrm{~cm}^{-1}$ (attributed to $\mathrm{C}-\mathrm{H}$ vibration of methyl and methylene) [50] and $v \mathrm{C}=\mathrm{O}$ vibration at $1680 \mathrm{~cm}^{-1}$ from PVP polymer (peaks display weaker intensities at $\sim 1661 \mathrm{~cm}^{-1}$ ) due to hydrogen bonding with the active and other co-polymers [53]. Although near identical peaks are observed between formulations and pristine samples, a new peak is observed between $1087-1113 \mathrm{~cm}^{-1}$, and is ascribed to carboxylic acid carbonyl stretching within copolymer molecules which may arise due to hydrogen bonding or Van der Waals forces.

\section{Contact angle measurements}

Contact angle measurements were used to assess film hydrophilicity as shown in Figure 7. Dynamic PBS contact angles on fabricated films were measured at 0, 2, 4 and 8 seconds. PBS contact angle on PVP-INDO fibrous film decreased from 68 to 59॰ over the assessment period. Upon the inclusion of co-polymers Methocel TM (E5) premium (F2) and Methocel TM (E15) (F3), the PBS contact angle changed from 68 to $47^{\circ}$ and from 74 to $47^{\circ}$, respectively. This suggests the inclusion of cellulose based co-polymers reduces PBS contact angle over time. A significant improvement to PVP-INDO samples wettability was noticed upon the inclusion of Tween ${ }^{\circledR} 80$; as the PBS contact angle decreased from 68 to $21^{\circ}$ for F4 and from 74 to $24^{\circ}$ for F5. Hence, Tween ${ }^{\circledR} 80$ enhances the hydrophilic property of fibrous films.

\section{Membrane-medium contact behavior}

To investigate structural change to fibrous components when in contact with test medium; pristine PVP fibres, PVP-INDO composite fibres and raw INDO powder was assessed using 
interfacing PBS medium. PVP fibres dissolved rapidly even at 1s and fibre integrity was compromised indicated by continuous threads transitioning into beaded structures (Figure $\mathbf{8 b}$ ), which then merge to form more coarse PVP particles. Inclusion of INDO into fibrous PVP matrices (Figure 8c) yield similar structures at the initial stage. When in contact with PBS, over designated time period, PVP dissolves leaving discrete PVP components. However, an indication of INDO precipitation is suspected (Figure 8c) with reduced PVP content; which eludes to the importance of both solubility (dispersion) and permeability. In comparison to raw INDO powder (Figure 8a), precipitates forming from rapid solubilisation of PVP are much smaller and therefore provide a greater surface area for interaction (i.e. for further INDO solubility).

\section{In vitro release studies}

Table 1 represents drug content in fibrous films which ranged from 2.89 to $4.93 \% \mathrm{w} / \mathrm{w}$. The values are less than the theoretical maxim $(5 \% \mathrm{w} / \mathrm{w})$ incorporated into ES formulations prior to processing. This is due to drug precipitation during the ES process or shortly thereafter. Moreover, samples prepared using co-polymer Methocel $^{\mathrm{TM}}(\mathrm{E} 15)$ reveal greater drug encapsulation compared to Methocel ${ }^{\mathrm{TM}}(\mathrm{E} 5)$.

Cumulative release profiles of various INDO formulations are illustrated in Figure 9 (a \& b). The presence of methyl cellulose results in a decrease in API release rate (formulations F2 \& F3) compared to the single polymer-drug system (PVP-INDO, F1).Here, sustained release is attributed to the non-soluble nature of cellulose based components. However, the sustained effect is less well pronounced when Methocel $^{\mathrm{TM}}$ (E5) is co-formulated in the film system. In this instance, $80 \%$ of drug is released within $2 \mathrm{~h}$, whereas when prepared using its congener (Methocel $\left.^{\mathrm{TM}}(\mathrm{E} 15)\right)$ only $60 \%$ of active is released. The higher release rate is linked to superior swelling behavior of Methocel ${ }^{\mathrm{TM}}$ (E5) arising from enhanced hydration rate,

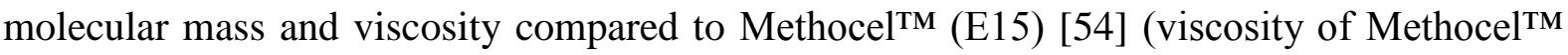
(E5) and Methocel $^{\mathrm{TM}}$ (E15) is 4-6 and 12-18, respectively [55]). The addition of non-ionic surfactant $\left(\right.$ Tween $^{\circledR} 80$ ) has little notable effect on INDO release (formulations F4 \& F5).

Higuchi kinetic model fitting was applied to in vitro drug release data (from engineered fibrous films). Drug release from all formulations showed two distinct release phases; an initial burst type release phase followed by a lag period. The Higuchi kinetic model fitting was applied to the initial phase. Correlation coefficient $\left(\mathrm{R}^{2}\right)$ and the release rate constant 
(K) are shown as insets in Figures 9 (a and $\mathbf{b})$. All formulations show high linearity with $\mathrm{R}^{2}$ $(>0.92)$. It can be concluded that the dominating mechanism for INDO release is fickian diffusion. However, the release rate is different for each formulation; where F1 possessed the greatest $\mathrm{K}$ value and $\mathrm{F} 5$ possessed the lowest $\mathrm{K}$ value.

\section{Transport studies}

The cumulative permeation profiles of tested formulations are shown in Figure 10. Comparable cumulative amounts of INDO across buccal epithelium were obtained for formulations F1, F2 and F3 (ca. $\left.24 \mu \mathrm{g} \mathrm{cm}^{-2} \mathrm{~h}^{-1}\right)$. The highest quantity of INDO transported across porcine mucosa was obtained for formulation $\mathrm{F} 4$; $\left(48.71 \mu \mathrm{g} \mathrm{cm}^{-2} \mathrm{~h}^{-1}\right)$ accordingly (not significantly different t-test $\mathrm{p}>0.05)$. These values might be explained considering the significant improvement of PVP-INDO wettability when Tween ${ }^{\circledR} 80$ was present allowing better adhesion of fibrous films to the mucosa. It should be noted that a lag time of $1 \mathrm{~h}$ for F4 and $2 \mathrm{~h}$ for all the rest formulations was noticed which is likely to be attributed to the slow mucosal adhesion process.

\section{Histological Evaluation}

Light microscopy studies were performed to further assess any histological changes upon application of tested formulations on to the surface of porcine buccal epithelium. When comparing the normal buccal non-keratinized epithelium (Figure 11A) with the F1 treated tissue (Figure 11B), desquamation of superficial keratinocytes and disorganization of collagen beneath basal membrane could be identified. In contrast, buccal non-keratinized epithelium after $6 \mathrm{~h}$ treatment with $\operatorname{Methocel}^{\mathrm{TM}}$ (E5) (F2) and $\operatorname{Methocel}^{\mathrm{TM}}$ (E15) (F3) revealed mild desquamation of superficial epithelium (Figure 11 C \& D). F2 formulational also showed mild disorganization at basal membrane. The most pronounced effect to epithelial alterations was observed for the $\mathrm{F} 4$ and $\mathrm{F} 5$ formulations. In case of Methocel $^{\mathrm{TM}}$ (E5)/Tween ${ }^{\circledR} 80$ (F4) was observed strong vacuolation of epithelial cells, and of Methocel ${ }^{\mathrm{TM}}$ (E15)/Tween ${ }^{\circledR} 80$ (F5) less vacuolation but with intense superficial desquamation. The histological findings show the effect of both types of Methocel ${ }^{\mathrm{TM}}$ and Tween ${ }^{\circledR} 80$, further corroborating the ex vivo data. 


\section{Conclusions}

The results show that various formulations of fibrous buccal patches containing INDO (as a model drug) can be easily engineered by means of the ES method into the amourphous state. The addition of Tween ${ }^{\circledR} 80$ to PVP-INDO formulations significantly improved their wettability. Patches containing methocel and Tween ${ }^{\circledR} 80$ were found to exhibit the highest permeation of INDO across porcine mucosa without significantly affecting the ultrastructure of the oral mucosa.

\section{$\underline{\text { Table and Figure Captions }}$}

\section{Tables}

Table 1. Formulated film sample compositions. All prepared using PVP (5 w/v \%) and INDO ( $5 \mathrm{w} / \mathrm{w} \%$ of PVP). Other excipients added in quantities shown as a function of $\mathrm{w} / \mathrm{w} \%$ of PVP. Calculated drug content within engineered samples.

\section{Figures}

Figure 1. Experimental set-up for electrspinning of fibrous films; (a) Apparatus showing position of nozzle (b) processing nozzle with no formulation flow (c) stable jetting at low voltage (d) stable jetting at increased voltage with change to cone-jet morhology (e) multijets arising from unstable processing.[scale bar $=3 \mathrm{~mm}$ ] (f) digital image of prepared films [scale bar $=2 \mathrm{~cm}]$.

Figure 2.Preparation of porcine ex-vivo permeation model and incorporation into diffusion cell showing (a) tissue preparation and (b) permeation assessment using Franz cells.

Figure 3.Electron micrographs of film samples and side view as insets for formulations $(\mathrm{F})$ : (A) F1 (B) F2 (C) F3 (D) F4 (E) F5. (F) and (G) show fibre diameter distributions of various spun films

Figure 4. X-ray diffractograms of (A) Pure Indomethacin (B) Methodcel E5 and (C) Methocel E15 samples.

Figure 5. Thermal analysis of engineered films and selected excipients using (A \& B) Differential scanning calorimetry and (C \& D) Thermal gravimetric analysis 
Figure 6. Spectroscopic analysis of engineered films and selected excipients using (A \& B) Raman and (C \& D) Fourier transform infra-red

Figure 7.PBS contact angle data on fibrous films. (A) Camera imaging sequences showing changes to droplet behaviour at film interface over time (B) \% change to contact angle from initial contact and (C) change to contact angle over time.

Figure 8. Electron micrographs showing PBS-film contact behaviour through changes to fibre structure over selected time intervals.

Figure 9.Release profiles of (A). F1, F2, F4, (B). F1, F3, F5 formulations in buffer pH=6.8. (mean \pm S.D., $\mathrm{n}=3$ ).

Figure 10.Cumulative permeated amount of indomethacin across porcine mucosa from various film samples.

Figure 11.Light micrographs of A. porcine buccal mucosa with non-keratinized epithelium (intact), B. F1 formulation, C. F2 formulation, D. F3 formulation, E. F4 formulation and F. F5 formulation (Magnification x100). 


\section{$\underline{\text { Tables and Figures }}$}

\section{$\underline{\text { Tables }}$}

Table 1

FORMULATION COMPOSITION

ID

F1

F2

F3

F4

F5

1

2

3

F5

PVP/INDO
PVP/INDO/Methocel TM (E5) 5\%
PVP/INDO/Methocel TM (E15) 5\%
PVP/INDO/Methocel
PVP $(E 5)$ 5\% / Tween ${ }^{\circledR} 80$

DRUG CONTENT (W/W \%)*

$4.43 \pm 0.21$

$2.89 \pm 0.85$

$4.10 \pm 0.02$

$3.35 \pm 0.49$

$3.75 \pm 0.39$

*INDO content in all formulation is 5\% w/w of PVP prior to processing. Drug content is based on the measured value after films have been formed.

*Tween ${ }^{\circledR} 80$ content in F4 and F5 is $5 \%$ w/w of PVP 


\section{$\underline{\text { Figures }}$}
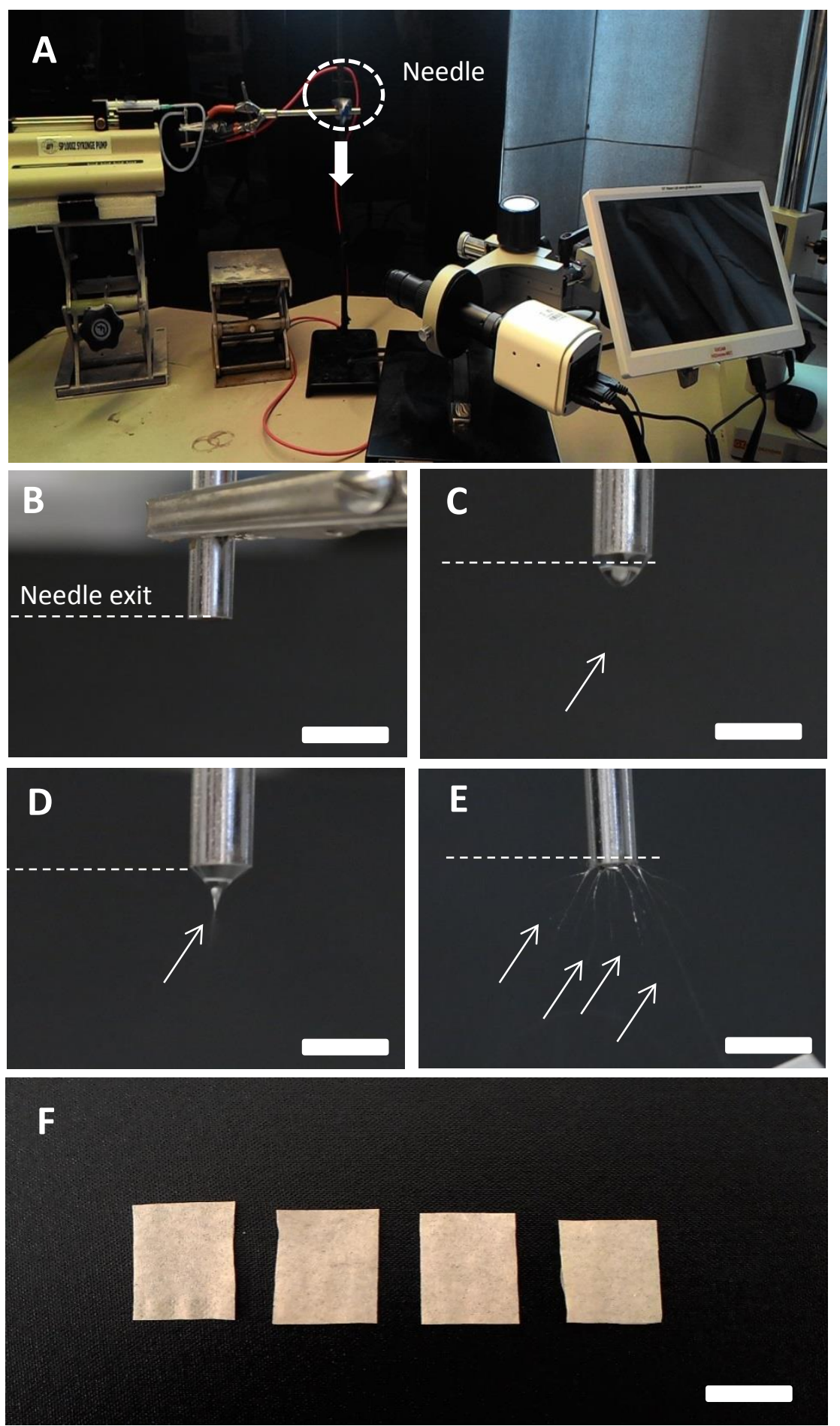

Figure 1 

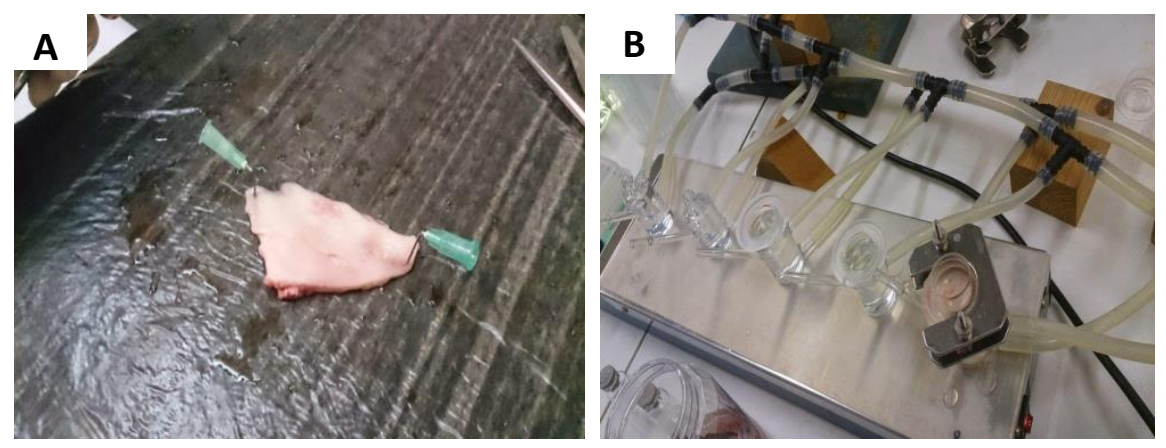

Figure 2 


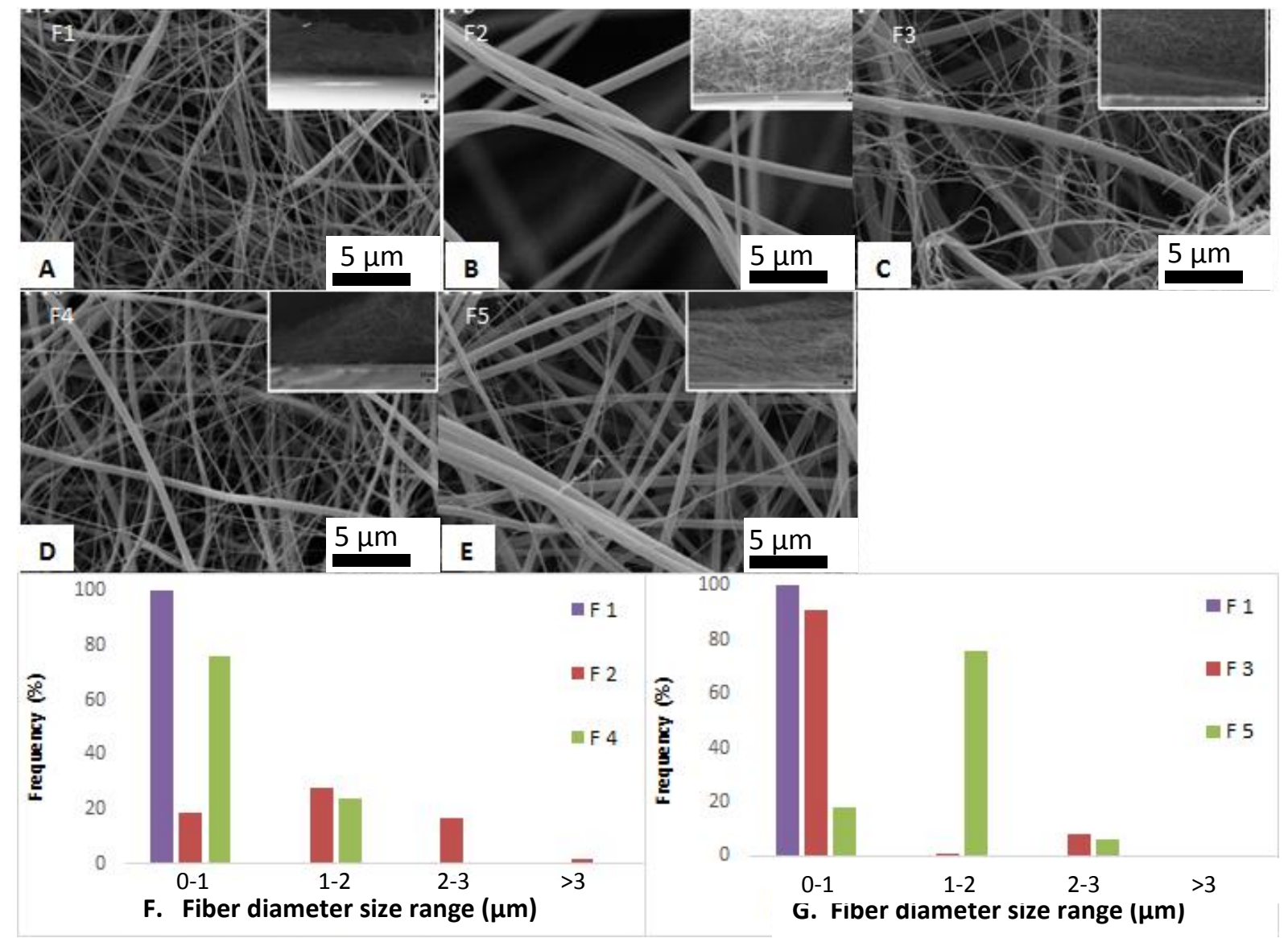

Figure 3 

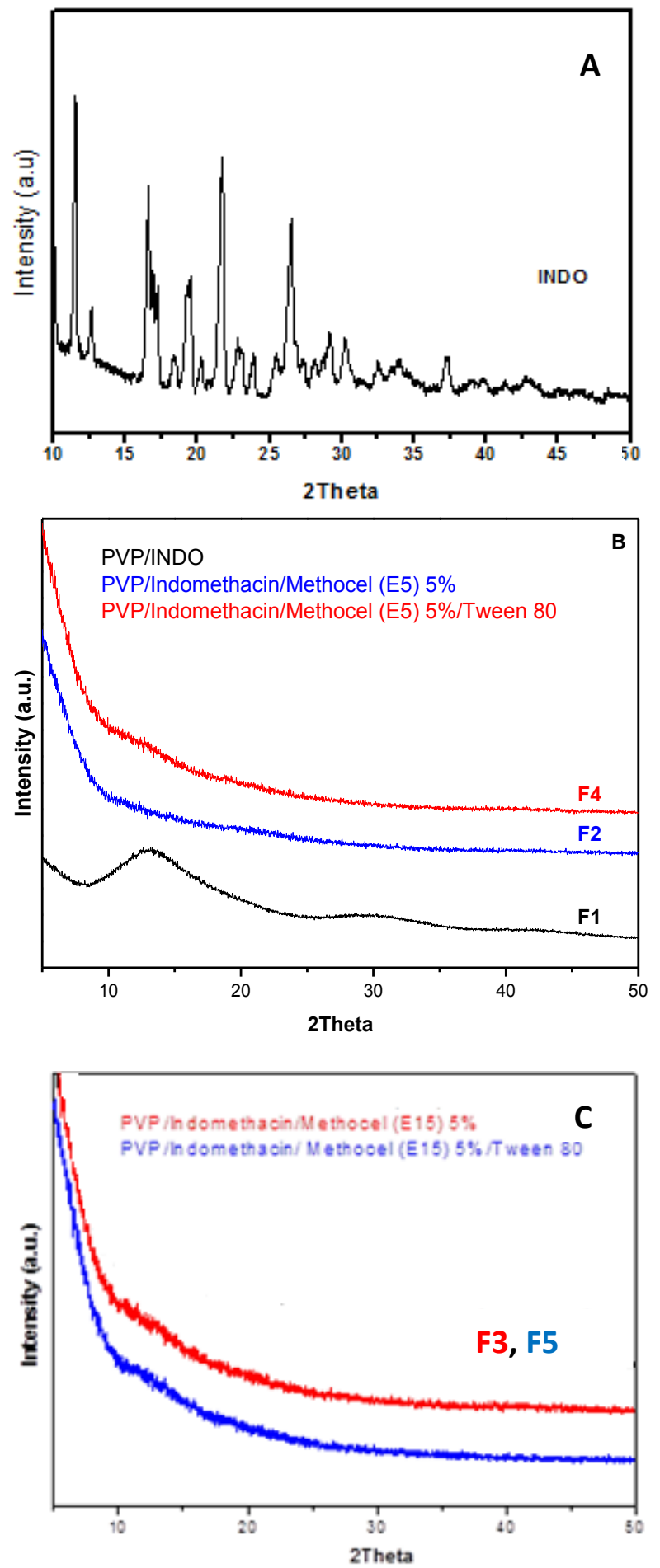

Figure 4 

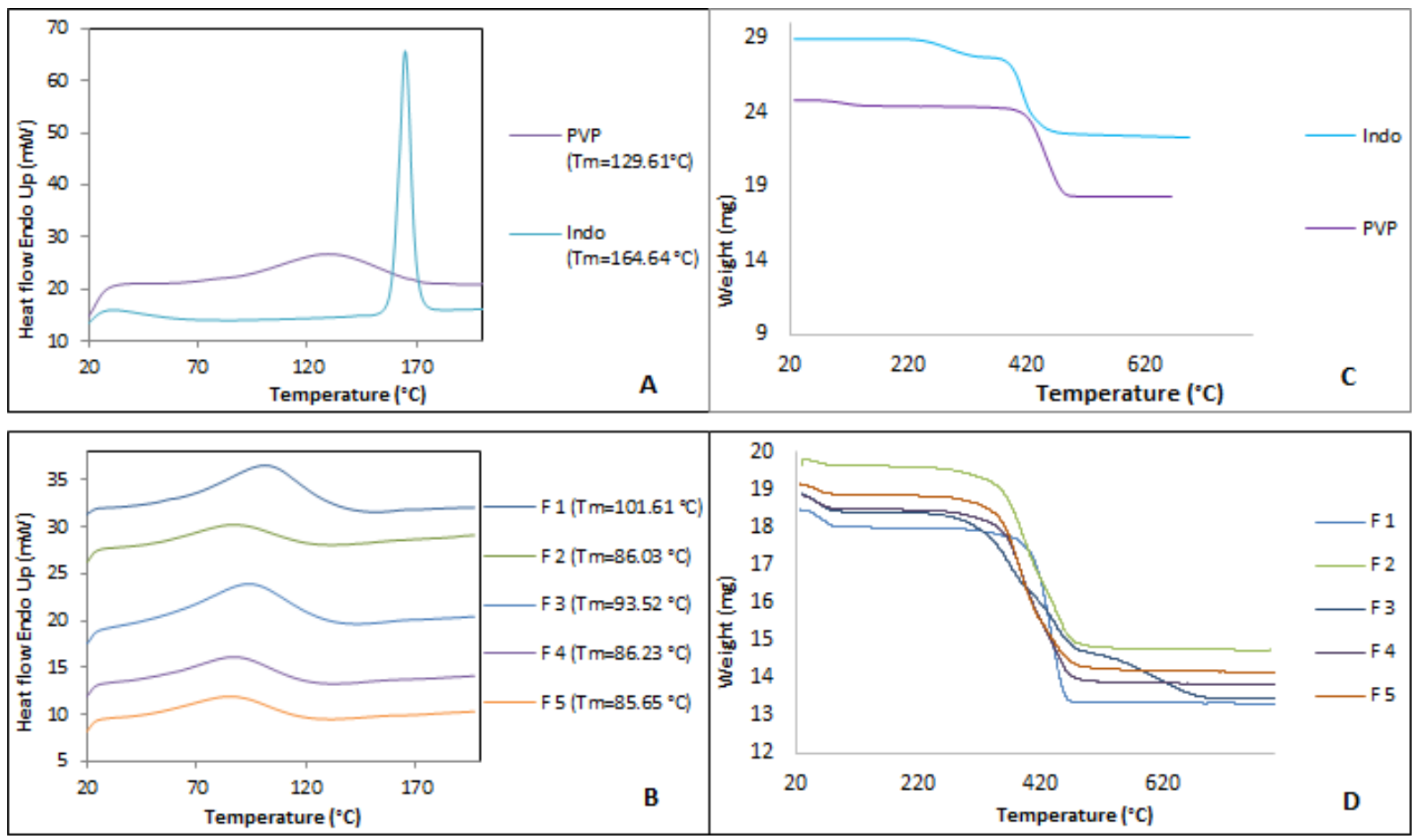

Figure 5 

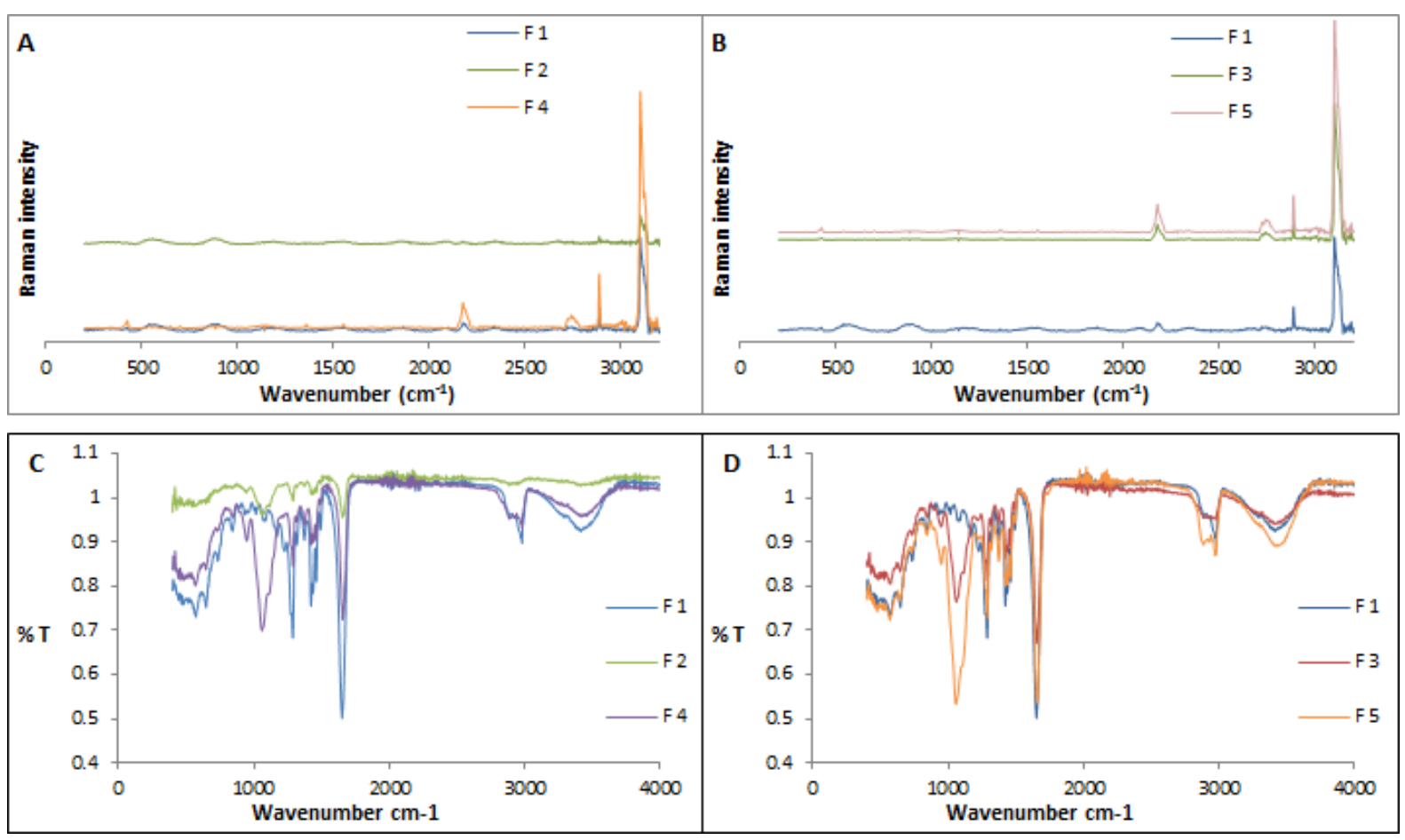

Figure 6 


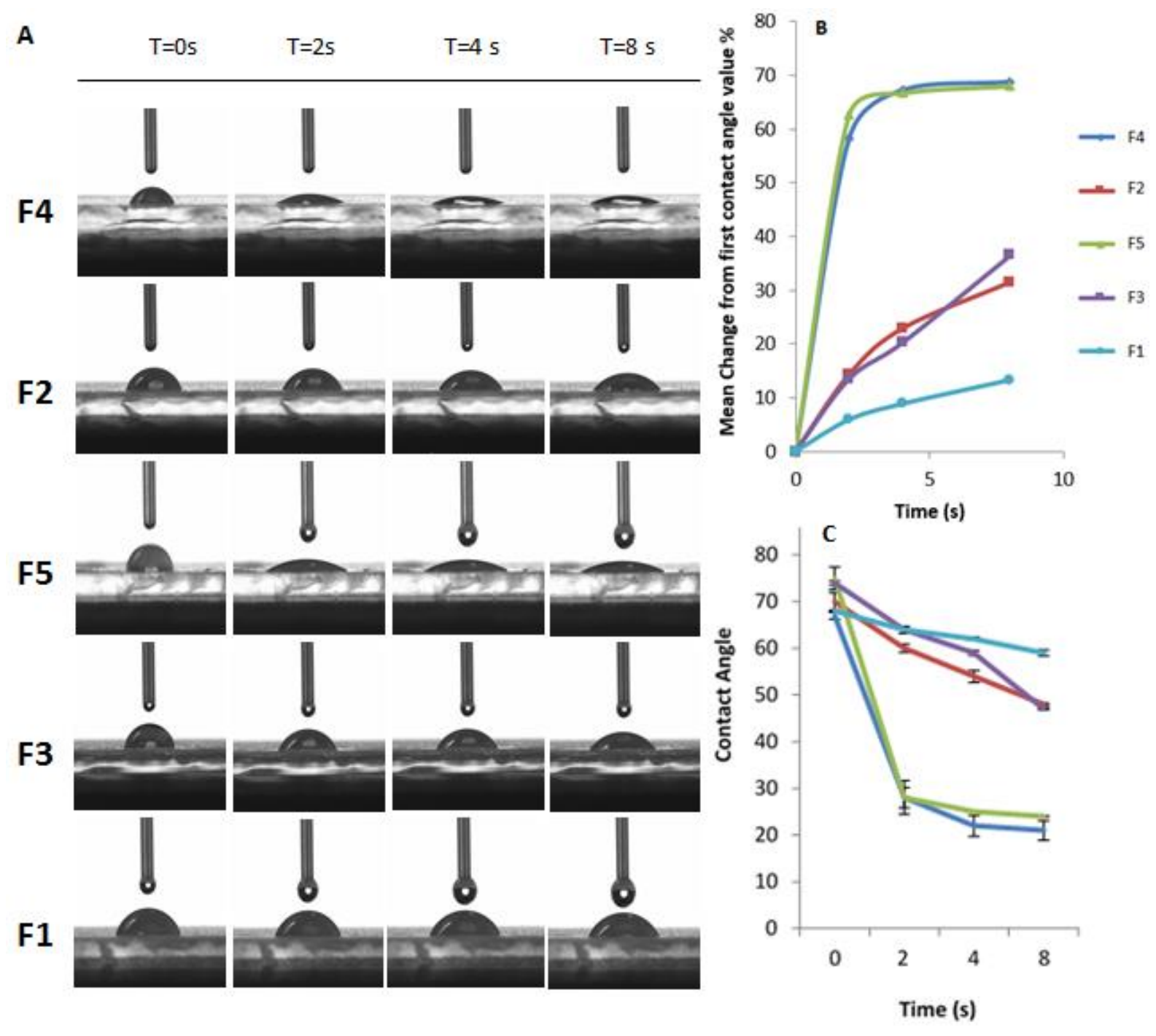

Figure 7 


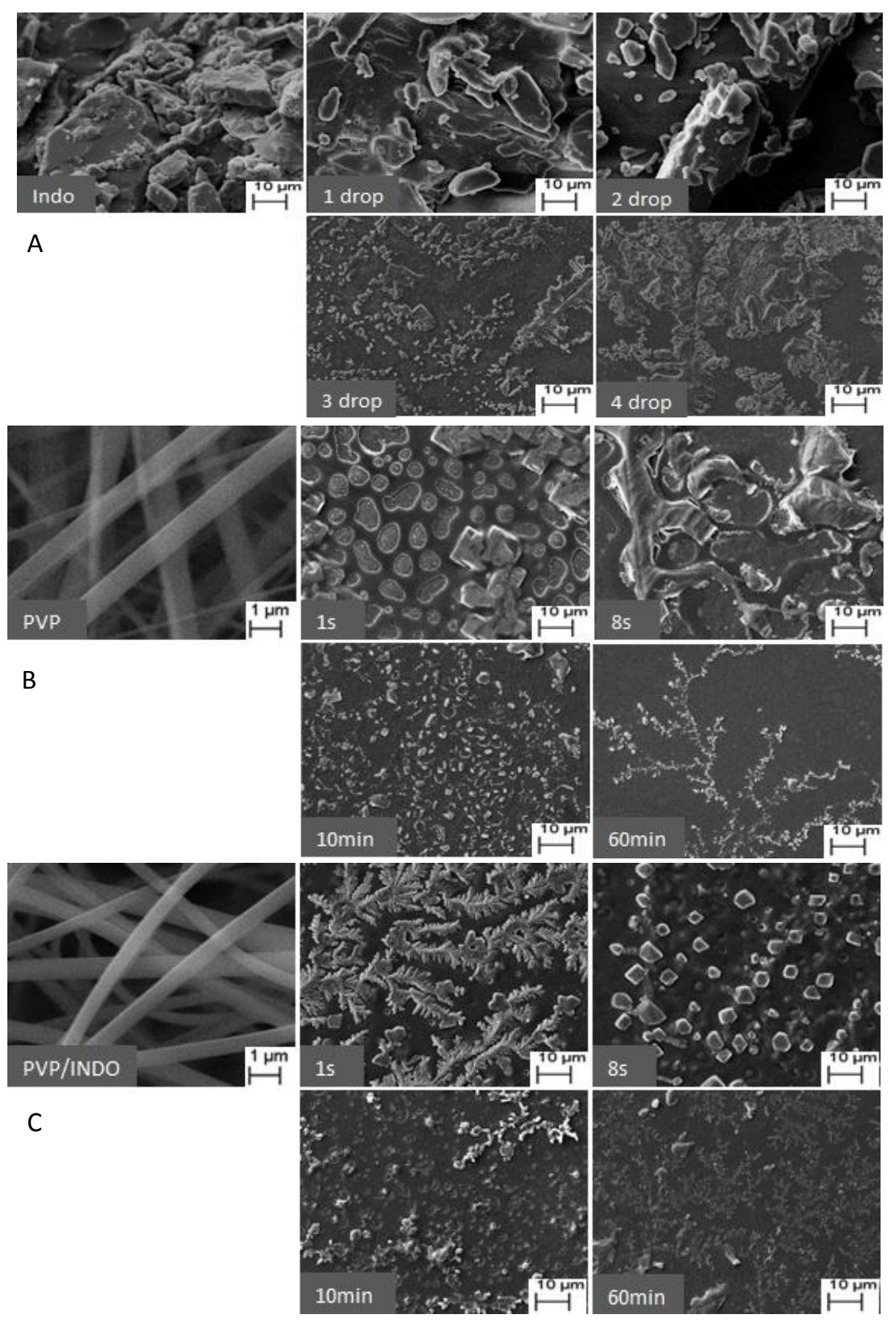

Figure 8 

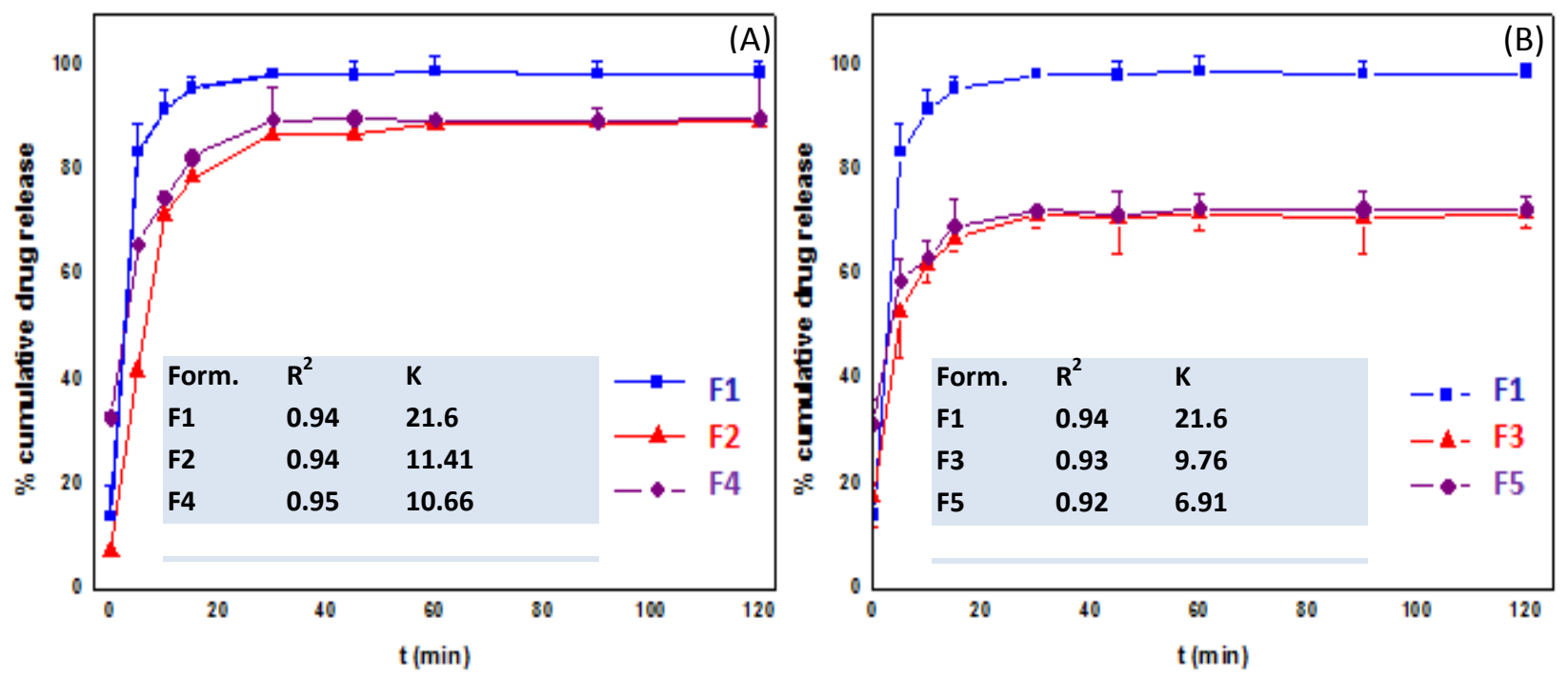

Figure 9 


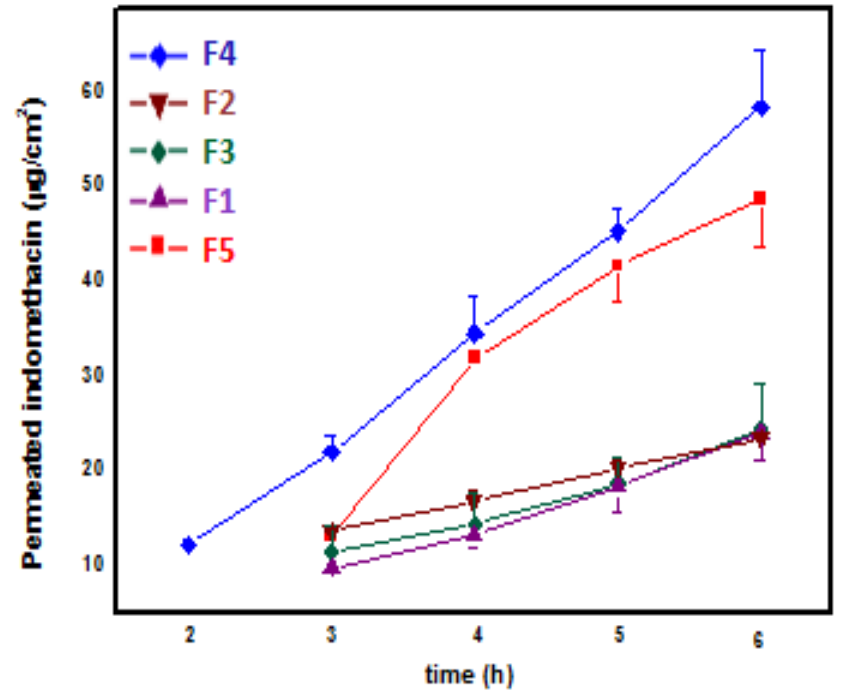

Figure 10 


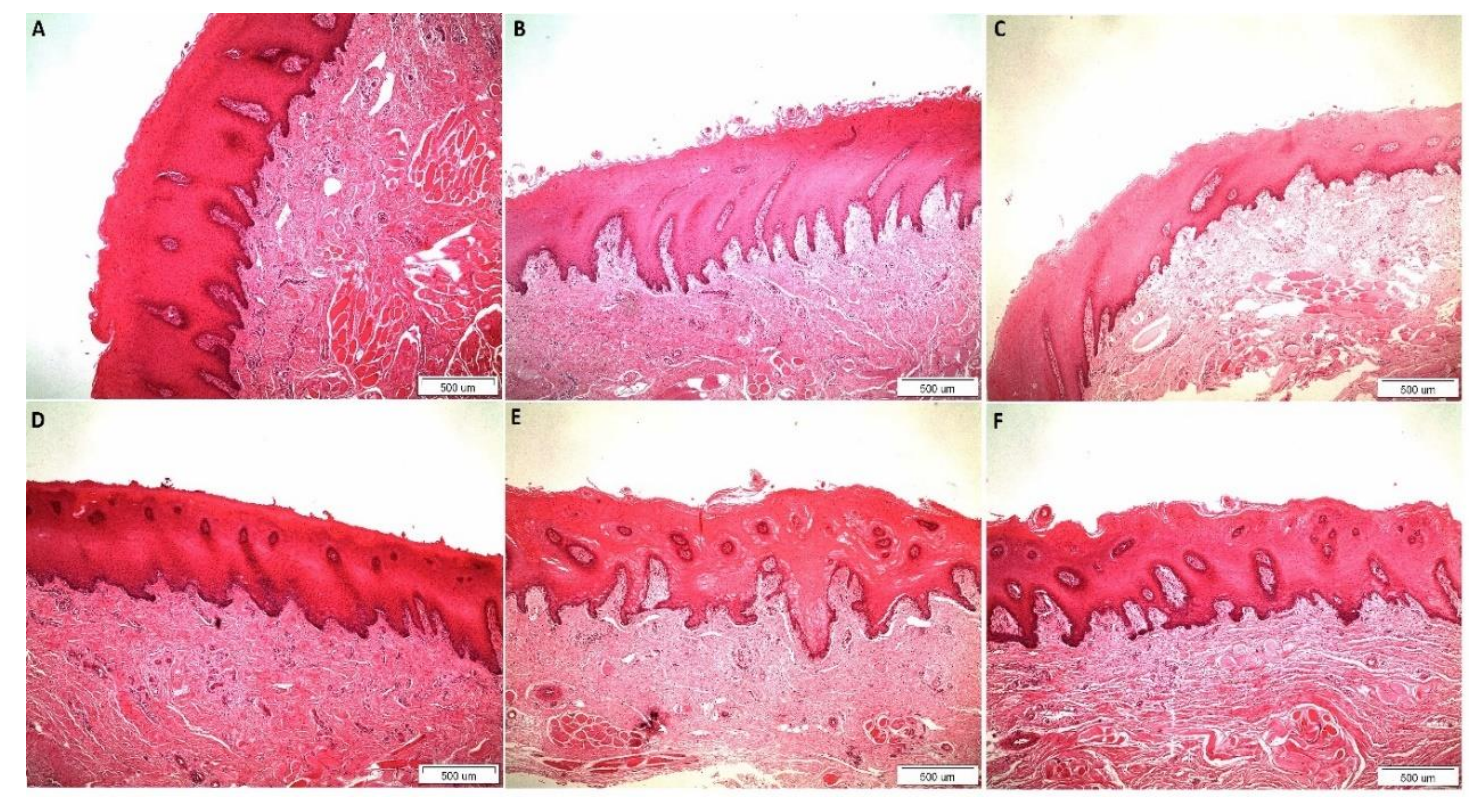

Figure 11 


\section{References}

[1] J. M. Ting, S. Tale, A. A. Purchel, S. D. Jones, L. Widanapathirana, High-Throughput Excipient Discovery Enables Oral Delivery of Poorly Soluble Pharmaceuticals. ACS Cent. Sci. 2 (2016) 748-755.

[2]. F. Hussain, M. Hojjati,M. Okamoto, R.E. Gorga, Polymer-matrix nanocomposites, processing, manufacturing, and application: An overview. J. Composite Mater. 40 (2006) $1511-1575$.

[3]. W.B. Liechty, D.R. Kryscio, B.V. Slaughter, N.A. Peppas, Polymers for drug delivery systems. Annu. Rev. Chem. Biomol. Eng.1 (2010) 149-173.

[4]. M.A.Repka,L. Chen, R.S. Chan, Buccal drug delivery, In: C.G. Wilson, P.J. Crowley (Eds.), Controlled Release in Oral Drug Delivery. Springer. (2011) 329-359.

[5]. P. Mura, M. Cirri, N. Mennini, G. Casella, F. Maestrelli, Polymeric mucoadhesive tablets for topical or systemic buccal delivery of clonazepam: Effect of cyclodextrin complexation. Carbohydr. Polym. 152(2016) 755-763.

[6]. N.R. Rao, B. Shravani, M.S. Reddy. Overview on buccal drug delivery systems. J.Pharm.Sci.\& Res. 5 (2013) 80-88.

[7]. F.L. Lopez, T.B. Ernest, C. Tuleu, M.O. Gul, Formulation approaches to pediatric oral drug delivery: Benefits and limitations of current platforms. Expert. Opin. Drug. Deliv. 12 (2015) 1727-1740.

[8]. K. Nazari, E. Kontogiannidou, R.Haj Ahmad, A. Gratsani,M. Rasekh, M.S. Arshad, B.S. Sunar, D. Armitage, N. Bouropoulos, M.W. Chang, Z. Li, D.G. Fatouros, Z. Ahmad, 
Development and characterisation of cellulose based electrospun mats for buccal delivery of non-steroidal anti-inflammatory drug (NSAID). Eur. J. Pharm. Sci. 102 (2017) 147-155.

[9]. A. Abruzzo, F. Bigucci, T. Cerchiara, F. Cruciani, B. Vitali, B. Luppi, Mucoadhesive chitosan/gelatin films for buccal delivery of propranolol hydrochloride. Carbohydr. Polym. 87 (2012) 581-588.

[10]. C.P. Reddy, K. Chaitanya, M.Y. Rao, A review on bioadhesive buccal drug delivery systems: Current status of formulation and evaluation methods. Daru. 19 (2011) 385-403.

[11]. S.L. Pather, M.J. Rathbone, S. Şenel, Current status and the future of buccal drug delivery systems. Exp. opin. drug deliv. 5 (2008) 531-542.

[12]. E. Marxen, M.C. Axelsen, A.M.L. Pedersen, J. Jacobsen, Effect of cryoprotectants for maintaining drug permeability barriers in porcine buccal mucosa. Int. J. Pharm. 511 (2016) $599-605$.

[13]. M.A. Attia,I. El-Gibaly, S.E. Shaltout, G.N. Fetih, Transbuccal permeation, antiinflammatory activity and clinical efficacy of piroxicam formulated in different gels. Int. J. Pharm. 276 (2004) 11-28.

[14]. A.H. Shojaei, R.K. Chang, X. Guo, B.A. Burnside, R.A. Couch, Systemic drug delivery via the buccal mucosal route. Pharm. Technol. 25 (2001) 70-81.

[15]. E. Meng-Lund, C, Muff-Westergaard, C. Sander, P. Madelung, J. Jacobsen, A mechanistic based approach for enhancing buccal mucoadhesion of chitosan. Int. J. Pharm. 461 (2014) 280-285. 
[16]. M. Radivojša Matanović, I. Grabnar, M. Gosenca, P. Ahlin Grabnar, Prolonged subcutaneous delivery of low molecular weight heparin based on thermoresponsive hydrogels with chitosan nanocomplexes: Design, in vitro evaluation, and cytotoxicity studies. Int. J. Pharm. 488 (2015) 127-135.

[17]. C.R. Palem, R. Gannu, V.V. Yamsani, S.K. Yamsani, M.R. Yamsani, Development of bilayered mucoadhesive patches for buccal delivery of felodipine: In vitro and ex vivo characterization. Curr.Trends Biotechnol.Pharm. 4 (2010) 673-683.

[18]. J. Mašek, D. Lubasová, R. Lukáč, P. Turánek-Knotigová, P. Kulich, J. Plocková, E. Mašková, L. Procházka, S. Koudelka, N. Sasithorn, J. Gombos, E. Bartheldyová, F. Hubatka,M. Raška, A.D. Miller, J. Turánek, Multi-layered nanofibrous mucoadhesive films for buccal and sublingual administration of drug-delivery and vaccination nanoparticles important step towards effective mucosal vaccines. J. Controlled Release. 249 (2017) 183195.

[19]. N. Bhardwaj, S.C. Kundu, Electrospinning: A fascinating fibre fabrication technique. Biotechnol. Adv. 28 (2010) 325-347.

[20]. P. Mehta, R. Haj-Ahmad, M. Rasekh, M.S. Arshad, A. Smith, S.M. van der Merwe, X. Li, M.W. Chang, Z. Ahmad, Pharmaceutical and biomaterial engineering via electrohydrodynamic atomization technologies. Drug Discov. Today. 22 (2017) 157-165.

[21]. D.H. Reneker, A.L. Yarin, Electrospinning jets and polymer nanofibres. Polymer. 49 (2008) 2387-2425.

[22].C.R. Jaeger, M.M. Bergshoef, C. Martin i Batlle, H.Schönherr, G.J.Vancso, Electrospinning of ultra-thin polymer fibres, Macromolecular Symposia, 127 (1998) 141-150 
[23]. N. Tomczak, N.F. van Hulst, G.J. Vancso, Beaded electrospun fibres for photonic applications. Macromolecul. 38 (2005) 7863-7866.

[24]. Y. Wu, R.L. Clark, Controllable porous polymer particles generated by electrospraying. J. Colloid Interface Sci. 310 (2007) 529-535.

[25]. J.C. Wang, H. Zheng, M.W. Chang,Z. Ahmad, J.S. Li,Preparation of active 3D film patches via aligned fibre electrohydrodynamic (EHD) printing. Sci. Rep. 7 (2017) 43924.

[26]. Z.Ekemen, H. Chang, Z.Ahmad,C. Bayram, Z. Rong, E.B. Denkbas, E. Stride,P. Vadgama, M. Edirisinghe, Fabrication of biomaterials via controlled protein bubble generation and manipulation. Biomacromolecul. 12 (2011) 4291-4300.

[27]. M. Rasekh, Z. Ahmad, R. Cross, J. Hernandez-Gil, J.D. Wilton-Ely, P.W. Miller, Facile preparation of drug-loaded tristearin encapsulated superparamagnetic iron oxide nanoparticles using coaxial electrospray processing. Mol. Pharm. 14 (2017) 2010-2023.

[28]. C. Zhang, Z. Yao, Q. Ding, J.J. Choi, Z.Ahmad, M.W.Chang, J. Li, The tri-needle coaxial electrospray engineering of magnetic polymer yolk-shell particles possessing dualimaging modality, multi-agent compartments and trigger release potential. ACS. Appl. Mater.\& Interfaces. 9 (2017) 21485-21495.

[29]. A. Inada, T. Oshima, H. Takahashi, Y. Baba, Enhancement of water solubility of indomethacin by complexation with protein hydrolysate. Int. J. Pharm. 453 (2013) 587-593.

[30]. A. Siddiqui, Z. Rahman, S.R. Khan, D. Awotwe-Otoo, M.A. Khan, Root cause evaluation of particulates in the lyophilized indomethacin sodium trihydrate plug for parenteral administration. Int. J. Pharm. 473 (2014) 545-551. 
[31]. A. Alqurshi, Z. Kumar, R. McDonald,J. Strang, A. Buanz, S. Ahmed, E. Allen, P. Cameron, J.A. Rickard, V. Sandhu, C. Holt, R. Stansfield, D. Taylor, B. Forbes, P.G. Royall. Amorphous formulation and in vitro performance testing of instantly disintegrating buccal tablets for the emergency delivery of naloxone. Molecul. pharm. 13 (2016) 1688-1698.

[32] E. Kenawy, G.L. Bowlin, K. Mansfield, J. Layman, D.G.Simpson, E. H.Sanders, G. E.Wnek, Release of tetracycline hydrochloride from electrospun poly(ethylene-covinylacetate), poly(lactic acid), and a blend, J. Control. Release. 81 (2002) 57-64.

[33] P. Mehta, A. A. Kinani, M.S. Arshad, M-w Chang, R.G. Alany, Z Ahmad, Development and characterisation of electrospun timolol maleate-loaded polymeric contact lens coatings containing various permeation enhancers, Int. J. Pharm -accepted http://dx.doi.org/10.1016/j.ijpharm.2017.09.029

[34] P. Mehta, A. A. Kinani, R. Haj-Ahmad, M.S. Arshad, M-w Chang, R.G. Alany, Z Ahmad, Electrically atomised formulations of timolol maleate for direct and on-demand ocular lens coatings, Eur. J. Pharm. Biopharm. 119 (2017) 170-184.

[35]. A. Jaworek, A. Krupa, Jet and drops formation in electrohydrodynamic spraying of liquids. A systematic approach. Exp. Fluids. 27 (1999) 43-52.

[36]. R. Bakhshi, M.J. Edirisinghe, A. Darbyshire0, Z. Ahmad, A.M. Seifalian, Electrohydrodynamic jetting behaviour of polyhedral oligomeric silsesquioxane nanocomposite. J. Biomater. Appl. 23 (2009) 293-309.

[37] K.Kataria, A.Gupta, G.Rath, R.B.Mathur, S.R.Dhakate, In vivo wound healing performance of drug loaded electrospun composite nanofibers transdermal patch. Int. J. Pharm. 469 (2014) 102-110. 
[38] D.R.Paul. Elaborations on the Higuchi model for drug delivery, Int. J. Pharm. 418 (2011) 13-17.

[39] S. DASH, P. N. MURTHY, L. NATH, P. CHOWDHURY, KINETIC MODELING ON DRUG RELEASE FROM CONTROLLED DRUG DELIVERY SYSTEMS. ACTA POLONIAE PHARMACEUTICA. 67 (2010) 217-223.

[40] A. Couto, R. Fernandes, M. Natália, S.Cordeiro, S. S.Reis, R. T.Ribeiroe, A.M. Pessoa, Dermic diffusion and stratum corneum: A state of the art review of mathematical models. J. Control. Release. 177 (2014) 74-83

[41] L.Y. Wang, J.K Ma, W.F. Pan, D. Toledo-Velasquez, C.J. Malanga, Y. Rojanasakul, Alveolar permeability enhancement by oleic acid and related fatty acids: evidence for a calcium-dependent mechanism. Pharm. Res. 11 (1994) 513-517.

[42] S. Arumuganathar, S. N. Jayasinghe, N. Suter, Aerodynamically assisted jet processing of viscous single- and multi-phase media. Soft Matter 3 (2007) 605-612.

[43] A. Jaworek, W. Balachandran, A. Krupa, J Kulon, W. Machowski, Electrohydrodynamic atomization of viscous liquids. Electrostatics 2003 (2004) 181-186.

[44] M. Nangrejo, Z. Ahmad, E. Stride, M. Edirisinghe, P. Colombo, Preparation of polymeric and ceramic porous capsules by a novel electrohydrodynamic process. Pharm. Dev. Technol. 13 (2008) 425-432.

[45] C. Zhang, M-w Chang, Z. Ahmad, W. Hu, D. Zhaoa, J-s Li. Stable single device multipore electrospraying of polymeric microparticles via controlled electrostatic interactions. RSC Adv. 5 (2015) 87919-87923. 
[46]. M.E. El-Naggar,A.M. Abdelgawad,C. Salas, O.J. Rojas, Curdlan in fibres as carriers of tetracycline hydrochloride: Controlled release and antibacterial activity. Carbohydr. Polym. 154 (2016) 194-203.

[47] D. G. Yu, W. Nie, L. M. Zhu and C. Branford-White, "Fast Dissolution Nanofiber Membrane of Ferulic Acid Prepared Using Electrospinning," $20104^{\text {th }}$ International Conference on Bioinformatics and Biomedical Engineering, Chengdu (2010) pp14

[48] R. N.Kamble, S. Gaikwad, A. Maske, S. S.Patil. Fabrication of electrospun nanofibres of BCS II drug for enhanced dissolution and permeation across skin. Journal of Advanced Research. 7 (2010) 483-489.

[49] X. Li, X. Wang, D. Yu, S Ye, Q Kuang, Q Yi, X Yao “Electrospun Borneol-PVP Nanocomposites. J. Nanomater. (2012), Article 731382,

[50]. W. Shi, W. Lu, L. Jiang, The fabrication of photosensitive self-assembly au nanoparticles embedded in silica nanofibres by electrospinning. J. Colloid. Interface Sci. 340 (2009) 291-297.

[51]. P. Taepaiboon, U. Rungsardthong, P. Supaphol, Drug-loaded electrospun mats of poly (vinyl alcohol) fibres and their release characteristics of four model drugs. Nanotechnol. 17 (2006) 2317-2329.

[52]. S. Baghel, H. Cathcart, N.J. O'Reilly, Polymeric amorphous solid dispersions: A review of amorphization, crystallization, stabilization, solid-state characterization, and aqueous solubilization of biopharmaceutical classification system class II drugs. J. Pharm. Sci. 105 (2016) 2527-2544. 
[53]. Y. Borodko, S.E. Habas, M. Koebel, P. Yang, H. Frei, G.A. Somorjai, Probing the interaction of poly(vinylpyrrolidone) with platinum nanocrystals by UV-Raman and FTIR. J. Phy. Chem. B. 103 (2006) 23052-23059.

[54] H. Suryakusuma, H.W. Jun,Encapsulated hydrophilic polymer beads containing indomethacin as controlled release drug delivery systems. J. Pharm. Pharmacol. 36 (1984) 497-501.

[55]. S. Verma, R. Gokhale, D.J. Burgess, A comparative study of top-down and bottom-up approaches for the preparation of micro/nanosuspensions. Int. J. Pharm. 380 (2009) 216-222. 